\title{
Multitasking in Daily Medical Activities: Improved Skill or Increased Risk?
}

\author{
Benini Federica ${ }^{1 *}$, Lanzarotto Francesco ${ }^{1}$, Moneghini Dario ${ }^{2}$, Missale Guido ${ }^{2}$, Munari Francesca ${ }^{3}$ \\ and Ricci Chiara ${ }^{1,3}$ \\ ${ }^{1}$ Gastroenterology Unit, ASST Spedali Civili of Brescia, Piazzale Spedali Civili, Italy \\ ${ }^{2}$ Digestive Endoscopy Unit, ASST Spedali Civili of Brescia. Piazzale Spedali Civili, Italy \\ ${ }^{3}$ Gastroenterology Unit, University of Brescia, Piazzale Spedali Civili, Italy
}

*Corresponding author: Benini Federica, Gastroenterology Unit - ASST Spedali Civili of Brescia, p.le Spedali Civili, 1 - 25123

Brescia, Italy

\section{ARTICLE INFO}

Received: May 11, 2020

Published: 畵 June 08, 2020

Citation: Benini Federica, Lanzarotto Francesco, Moneghini Dario, Missale Guido, Munari Francesca, Ricci Chiara. Multitasking in Daily Medical Activities: Improved Skill or Increased Risk?. Biomed J Sci \& Tech Res 28(1)-2020. BJSTR. MS.ID.004605.

\section{ABSTRACT}

A 68-year-old man with liver cirrhosis was admitted for capsule endoscopy because of severe anemia due to overt gastrointestinal bleeding. A capsule enteroscopy was already performed two years earlier for the same reason and the procedure had no complications. He was referred to our Centre after a colonoscopy and an upper endoscopy reported no bleeding signs, but the upper endoscopy revealed the presence of a Zencker diverticulum, that was not reported during the medical history taking. The patient swallowed the capsule with no problems, and the recording showed persistent esophageal mucosa images: it was suspected the capsule to be stuck in a Zenker diverticulum. A neck Rx was performed, showing a radiopaque foreign body, compatible with the capsule, retained in the patient's neck. The patient underwent upper endoscopy, and the capsule was extracted after several efforts. On the subsequent days, the patient had an uneventful course and was discharged in stable clinical conditions. Medical history taking is one of the main basis of every medical procedures, but physicians can overlook it if multitasking is required and interruptions in medical activity happens.

\section{Introduction}

Zenker's diverticulum is a rare condition with a reported prevalence ranging between 0.01 to $0.11 \%$ in Europe. Typical symptoms include dysphagia, regurgitation, chronic cough, aspiration, and weight loss; however, it can remain asymptomatic for years [1]. Visualization of the digestive tract through the use of endoscopic capsule is one of the safest procedures and is performed routinely. Capsule retention is the main complication and it is described in 1-2\% of procedures (primarily in diverticula of the small bowel, in previous intestinal resections or in Crohn disease) [2], but there are only a few case reports of a capsule retained in a Zenker's diverticulum [3-5]. We present here a case of a capsule retention in a Zenker diverticulum, with the peculiarity that the retention could be avoided if the attending physician had paid more attention and time to the patient's clinical history. The case highlights the risks related to a multitasking and overload physician's activity.

\section{Case Presentation}

A 68-year-old man affected by liver cirrhosis was admitted for capsule endoscopy because of severe anemia due to overt gastrointestinal bleeding. A capsule enteroscopy was already performed two years earlier for the same reason and the procedure had no complications, showing the presence of petechiaes in the small bowel as sign of portal hypertension. After starting beta blockers therapy the patient had no more episodes of anaemia for the subsequent 18 months; anyway, blood transfusions have been necessary because of overt bleeding in the last 6 months. For this reason, he was referred to our Centre for capsule enteroscopy after a colonoscopy and an upper endoscopy reported no bleeding signs. Actually, the upper endoscopy revealed the presence of a Zencker diverticulum; moreover, an $\mathrm{Rx}$ of the esophagus confirmed its presence; nevertheless, the patients did not mention it and didn't show any records to the physician during the interview before 
the procedure. The patient swallowed the capsule (Pillcam SB3, Medtronic) smoothly without real-time monitoring. The capsule recording was examinated on the following day, and showed persistent esophageal mucosa images, so it was suspected to be stuck in a Zenker diverticulum. The patient was asymptomatic, but he was unable to report capsule excretion. A neck radiograph was performed, showing a radiopaque foreign body, compatible with the capsule, retained in the patient's neck. Due to the risk of a spontaneous expulsion of the capsule in the upper airways, it was decided to remove it. The patient underwent upper endoscopy, and the capsule was extracted after several efforts (Figures 1 \& 2). On the subsequent days, the patient had an uneventful course and was discharged in stable clinical conditions.

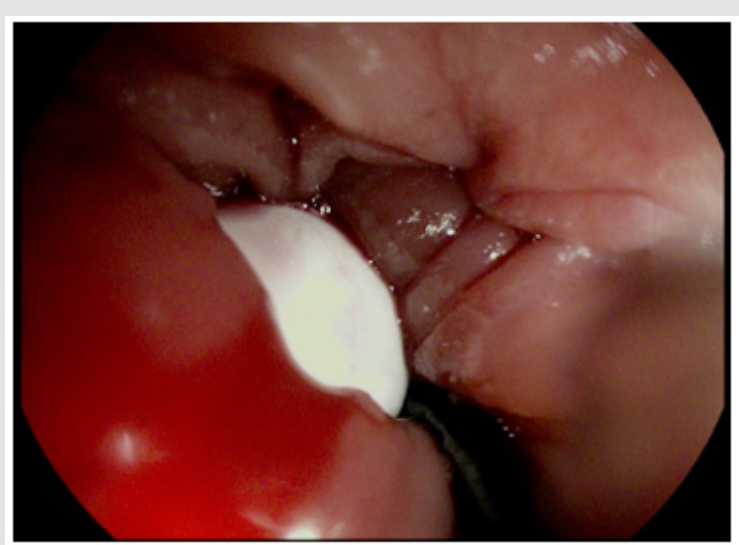

Figure 1: The capsule inside the Zenker diverticulum.

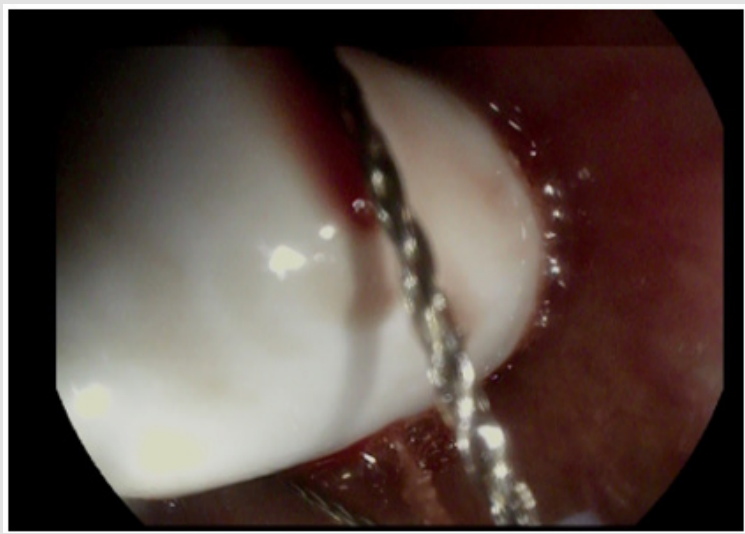

Figure 2: The extraction of the capsule from the Zenker diverticulum.

\section{Discussion}

The clinical case that we present is significative because represents a dangerous situation due to inaccuracy, mainly due to high work rhythms. The attending physician did not pay enough attention to the investigations recently performed because of a previous enteroscopy free of complications and he did not take a carefull clinical history because the enteroscopy was performed on saturday, during a ward turn, to short waiting lists. Multitasking is a valued skill in the clinical setting allowing for the efficient execution of daily activities, but it may fail to be an effective mechanism in clinical practice when it leads to cognitive overload [6]. Interruptions and multitasking are frequent in clinical settings, and have been shown to affect performance, increasing the risk of error [7]. This is critically important for tasks that involve specific, ordered steps such as medical procedures, and is highly relevant during medical ward turns, in which both procedures and interruptions are common occurrences. Interruptions occurring just before task completion or during a key step in a task increase the risk of error through task component incompletion. Individual physicians apply various strategies to manage their workload in the face of often unpredictable demands to deliver safe care to patients [8].

The success of their task management will be influenced by their individual choices and the way in which team members interrelate to them. In order to optimize safe and efficient patient care, efforts to promote successful simultaneous task completion are needed. Techinques that can develop effective task-switching skills exist. Team members should train to recognize the signs of high-risk distraction times and practice how to deal with these conditions safely. The environment can be optimized to decrese interruptions and increase reminders to return to incomplete tasks. Tools in the electronic medical record can streamline common work and provide reminders of common processes. This report is to reiterate that one of the cornerstones of medicine is competency in medical history taking, and to warn that multitasking often increases risks and does not always reduce costs.

\section{Declaration of Competing Interest}

All authors declare: no support from any organization; no financial relationships with any organizations that might have an interest in the submitted work in the previous five years; no other associations or activities that could appear to have influenced the submitted work. Hence, all authors declare themselves independent of funders concerning this manuscript.

\section{References}

1. Law R, Katzka DA, Baron TH (2014) Zenker's diverticulum. Clinical Gastroenterology and Hepatology 12(11): 1773-1782.

2. Mustafa BF, Samaan M, Langmead L, Khasraw M (2013) Small bowel video capsule endoscopy: an overview. Expert Review of Gastroenterology and Hepatology 7(4): 323-329.

3. Aabakken L, BlomhoffJP, Jermstad T, Lynge AB (2003) Capsule endoscopy in a patient with Zenker's diverticulum. Endoscopy 35(9): 799.

4. Rondonotti E, Cengia G, Bonfante F (2017) Err human est, persevere diabolicum autem. Gastroenterology 153: 23-24.

5. Simmons DT, Baron TH (2005) Endoscopic retrieval of a capsule endoscope from a Zenker's diverticulum. Diseases of the esophagus 18(5): 338-339

6. Laxmisan A, Hakimzada F, Sayan O, Green R, Zhang J (2007) The multitasking clinician: decision-making and cognitive demand during and after team handoffs in emergency care. International Journal of Medical Informatics 76(11-12): 801-811. 
7. Flynn EA, Barker KN, Gibson JT, Pearson RE, Berger BA (1999) Impact of the interruptions and distractions on dispensing errors in an ambulatory care pharmacy. Am J Health Syst Pharm 56(13): 1319-1325.

ISSN: $2574-1241$

DOI: 10.26717/BJSTR.2020.28.004605

Benini Federica. Biomed J Sci \& Tech Res

(C) 9 This work is licensed under Creative

Submission Link: https://biomedres.us/submit-manuscript.php
8. Wears RL, Woloshynowych M, Brown R, Vincent CA (2010) Reflective analysis of safety research in the hospital accident \& emergency departments. Appl Ergon 41(5): 695-700.

$\begin{array}{ll}\text { BIOMEDICAL } & \text { Assets of Publishing with us } \\ \text { RESEARCHES } & \text { - Global archiving of articles } \\ \text { - Immediate, unrestricted online access }\end{array}$

